\section{Agreement between specially trained and accredited optometrists and glaucoma specialist consultant ophthalmologists in their management of glaucoma patients}

\begin{abstract}
Aims Optometrists are becoming increasingly involved in the co-management of glaucoma patients as the burden on the Hospital Eye Service continues to escalate. The aim of this study was to assess the agreement between specially trained optometrists and glaucoma-specialist consultant ophthalmologists in their management of glaucoma patients.

Methods Four optometrists examined 23-25 patients each and the clinical findings, up to the point of dilation, were documented in the hospital records. The optometrist, and one of two consultant ophthalmologists, then independently examined and documented the optic-disc appearance before recording their decisions regarding the stability and management of the patient on a specially designed proforma. Percentage agreement was calculated together with kappa or weighted kappa statistics, where appropriate. Results Agreement between consultants and optometrists in evaluating glaucoma stability was $68.5 \%$ (kappa $(\kappa)=0.42-0.50)$ for visual fields, $64.5 \%$ (weighted $\kappa=0.17-0.31$ ) for optic discs, and $84.5 \%$ (weighted $\kappa=0.55-0.60$ ) for intraocular pressures. Agreement regarding medical management was $96.5 \%$ ( $\kappa=0.73-0.81$ ) and for other glaucoma management decisions, including timing of follow-up, referral to a consultant ophthalmologist, and discharge, was $72 \%$ (weighted $\kappa=0.65$ ). This agreement increased to $90 \%$ following a retrospective independent then consensus review between the two
\end{abstract}

JR Marks' ${ }^{1}$, AK Harding ${ }^{1}$, RA Harper ${ }^{1}$, E Williams ${ }^{1}$, $S^{S}$ Haque $^{2}$, AF Spencer ${ }^{1}$ and $C$ Fenerty ${ }^{1}$ consultants and when qualified agreements were included. Of the 47 glaucoma and nonglaucoma queries generated during the study, 42 resulted in a change of management. Conclusion Confirming the ability of optometrists to make appropriate decisions regarding the stability and management of glaucoma patients is essential if their involvement is to continue to develop to meet the demand of an aging population. Eye (2012) 26, 853-861; doi:10.1038/eye.2012.58; published online 13 April 2012

Keywords: glaucoma; shared care; specialist optometrist; glaucoma-specialist consultant ophthalmologist; agreement

\section{Introduction}

The need for non-medical healthcare professionals to become more involved in the co-management of glaucoma in the United Kingdom has become increasingly apparent. In June 2009, the National Patient Safety Agency issued an alert following reports of 44 glaucoma patients who had experienced vision loss as a result of delayed follow-up appointments. ${ }^{1}$ This alert came just 2 months after the publication of the National Institute for Health and Clinical Excellence (NICE) glaucoma guideline, which stated that 'there are not enough ophthalmologists at present to do all the work required so the work needs to be shared'. ${ }^{2}$ Optometrists are particularly well placed to take
${ }^{1}$ Manchester Royal Eye Hospital, Manchester, UK

${ }^{2}$ Health \& Population Sciences, University of Birmingham, Birmingham, UK

Correspondence: JR Marks, Optometric-Led Glaucoma Assessment (OLGA) Clinic, Eye G, Manchester Royal Eye Hospital, Oxford Road, Manchester, M13 9WL, UK Tel: + 44 (0)161 276 5535; Fax: + 44 (0)161 2765643 . E-mail: joanne.marks@ cmft.nhs.uk

Received: 7 November 2011 Accepted in revised form: 24 February 2012 Published online: 13 April 2012 
on this role as they already possess many of those fundamental skills required to examine a glaucoma patient. In 2003, the Optometric-Led Glaucoma Assessment (OLGA) clinic at the Manchester Royal Eye Hospital was established to monitor low-risk glaucoma, glaucoma suspect, and ocular hypertensive patients as a means of increasing appointment availability within the consultant-led clinics for more complex cases and new referrals. This independently run, stand-alone service, which has been described in detail elsewhere, ${ }^{3}$ currently provides $\sim 4500$ additional glaucoma follow-up appointments per year, both within the hospital and at satellite community clinics. Optometrists employed within the service undergo extensive in-house training under the guidance of two glaucoma-specialist consultant ophthalmologists and are required to complete the College of Optometrists Diploma in Glaucoma (Certificates A and B). Results of previous audits (unpublished) have shown that the clinical assessment of patients within the OLGA clinic is not only of a high standard but also is more consistent than in general ophthalmology clinics and patient satisfaction is high. However, if services like OLGA are to be expanded and established elsewhere, it is clearly important to ascertain whether specialist optometrists, with the appropriate training, qualifications, and experience, are able to make glaucoma management decisions that are in close agreement with those of specialist consultant ophthalmologists who are ultimately responsible for the patients.

\section{Materials and methods}

The study (registered as an internal audit) was divided into two parts. In the first part, decisions regarding the stability and management of glaucoma patients made by the OLGA-trained optometrists, all of whom had the DipGlauc qualification, were evaluated against those of two glaucoma-specialist consultant ophthalmologists acting as the reference standard. The second part of the study was designed to evaluate the ability of the optometrists to correctly identify glaucomatous and co-existing pathology requiring a more specialist opinion and/or intervention.

\section{Part one: glaucoma clinical management decisions- agreement between specialist optometrists and glaucoma-specialist consultant ophthalmologists}

Patient allocation. Between 1 February 2008 and 6 May 2008, 18 regular OLGA clinics were pre-allocated as 'audit' sessions. Allocation was designed to ensure approximately equal numbers of patients from each of the four optometrists working in the OLGA service at the time of the study and the two participating consultant ophthalmologists. Patients were booked according to the waiting-list order and all the OLGA patients attending an allocated session were included, provided that they were being seen for a full, scheduled visit, that is, not for a repeat visual field (VF) or intraocular pressure (IOP) check.

Recording clinical management decisions. Each patient performed a Humphrey 24-2 SITA-standard VF examination unless their vision was too poor, they were physically incapable of performing a VF or they had previously been documented as being consistently unreliable such that VF assessment was no longer appropriate. A 10-2 strategy was employed for those patients with advanced field loss involving the central $10^{\circ}$. The patient was subsequently assessed by the optometrist, in accordance with the OLGA protocol, ${ }^{3}$ up to the point where their pupils were dilated in preparation for optic disc and fundus assessment. This initial assessment includes a full history and symptoms (incorporating a review of treatment adherence, persistence, and side effects and changes in risk factors, general health, and systemic medication), logMAR acuity, slit-lamp anterior segment assessment, Goldmann tonometry, ultrasound pachymetry (if not done previously), and gonioscopy, which is performed at baseline and then at least once every 3 years or when indicated. The optometrist completed the standard OLGA clinic proforma in the hospital notes up to this stage. Once the patient's pupils were dilated, the optometrist and one of the two glaucoma-specialist consultant ophthalmologists, separately and independently, examined and documented the optic-disc appearance using slit-lamp binocular indirect ophthalmoscopy before making decisions regarding the stability of the VF, optic discs, and IOP, and the planned patient management including any changes to medical treatment, timing of follow-up, referral of the patient to their consultant for either a glaucoma- or non-glaucomarelated problem, planned tests such as repeat fields, pressures, or phasing or discharge. This information was recorded on a separate proforma (Figure 1). The ophthalmologists formulated their decisions from the perspective of an optometrist working within the clinical parameters of the OLGA service. At the time of the study, monoscopic colour optic-disc photography was performed at the initial OLGA visit then at alternate visits thereafter or as often as indicated, for example, disc haemorrhage documentation. Both ophthalmologist and optometrist had full access to patient notes and previous photographs but were masked to each other's optic-disc assessment and management decisions for that visit.

Data management and analysis. Results from the optometrists were pooled, as were those from the two consultant ophthalmologists, and inter-optometrist/ 


\begin{tabular}{|c|c|c|}
\hline Patient ID & Examiner & \\
\hline VISUAL FIELD STATUS (Select the single most suitable option) & RIGHT & LEFT \\
\hline Definitely stable & $\square$ & $\square$ \\
\hline Variable but probably stable & $\square$ & $\square$ \\
\hline Variable but probably progressing & $\square$ & $\square$ \\
\hline Definitely progressing & $\square$ & $\square$ \\
\hline Unreliable/insufficient data & $\square$ & 口 \\
\hline Non-glaucomatous field loss & $\square$ & 口 \\
\hline \multicolumn{3}{|l|}{ OPTIC DISC STATUS (Select the single most suitable option) } \\
\hline Definitely stable & $\square$ & 口 \\
\hline Probably stable, limited previous data & $\square$ & $\square$ \\
\hline Probably progressing, limited previous data & $\square$ & $\square$ \\
\hline Definitely progressing & $\square$ & $\square$ \\
\hline \multicolumn{3}{|l|}{ INTRAOCULAR PRESSURE STATUS (Select the single most suitable option) } \\
\hline IOP within target/acceptable for degree of disc/field damage & $\square$ & $\square$ \\
\hline IOP borderline & $\square$ & 口 \\
\hline IOP outside target/not acceptable for degree of disc/field damage & $\square$ & $\square$ \\
\hline \multicolumn{3}{|c|}{ CLINICAL MANAGEMENT 1 (TREATMENT) (Select the single most suitable option) } \\
\hline Continue current treatment (includes no treatment) & $\square$ & $\square$ \\
\hline Start treatment & $\square$ & $\square$ \\
\hline Change/add treatment & $\square$ & $\square$ \\
\hline Reduce treatment & $\square$ & $\square$ \\
\hline \multicolumn{3}{|l|}{ CLINICAL MANAGEMENT 2 (ACTION) (Select all suitable options) } \\
\hline Consider discharge & $\square$ & $\square$ \\
\hline Continue to monitor in OLGA (same or extended follow-up) & $\square$ & $\square$ \\
\hline Continue to monitor in OLGA (reduced follow-up) & $\square$ & 口 \\
\hline Discuss with consultant - ok to continue monitoring Px in OLGA? & $\square$ & $\square$ \\
\hline $\begin{array}{l}\text { Refer back to consultant for glaucoma related problem e.g. IOP, disc/VF } \\
\text { progression, PI's, side effects with drops }\end{array}$ & $\square$ & 口 \\
\hline \multicolumn{3}{|l|}{ PLANNED TESTS (Select all suitable options) } \\
\hline Repeat VF & $\square$ & $\square$ \\
\hline Repeat IOP & $\square$ & $\square$ \\
\hline Phasing & $\square$ & 口 \\
\hline
\end{tabular}

Figure 1 Audit proforma.

consultant agreement assessed for each management decision. Percentage agreement, kappa $(\kappa)$, and weighted kappa statistics were calculated for a range of parameters. Weighting was based on a system described by Banes et al, ${ }^{4}$ that is, 1.0 for agreement, 0.75 for one-step away disagreement, 0.50 for two steps, 0.25 for three steps, and 0.00 for four or more steps.
Retrospective case note and consensus review. In those cases where the clinical management plan proposed by the optometrist and the consultant differed, the patient notes and photographs were retrospectively reviewed by the second consultant who completed a separate proforma. The second consultant was masked to the management decisions of both the optometrist and the first consultant 
but had access to the optic-disc drawings of the first consultant. In the event of a disagreement between all three of the clinicians, the two consultants collectively reviewed the patient notes, in conjunction with the original management decisions of both the consultants and the optometrist, before reaching a consensus decision and making a qualitative judgement as to whether the optometrist's original decisions were considered to be acceptable, undercautious, or overcautious.

\section{Part two: analysis of queries/referrals from the OLGA clinic}

During the study period, any OLGA patient, who was not seen in one of the 'audit' clinics but was being referred back to their registered consultant for opinion and/or intervention regarding a glaucoma- or nonglaucoma-related issue, was either examined by one of the glaucoma specialists during a designated audit clinic session or their notes were retrospectively reviewed to determine referral appropriateness. The consultant documented whether they agreed, partly agreed, or disagreed with the optometrist's reason for referral and their planned management and whether the patient's management was altered as a result of the referral or query.

We certify that all the applicable institutional and governmental regulations concerning the ethical use of human volunteers were followed during this research.

\section{Results}

\section{Part one}

Biographical data. In total, 98 eligible patients attended the allocated clinics but 2 were excluded from the analysis-one had health problems that prevented them from completing the clinical examination, whereas the other left before being seen by the consultant. Patient distribution was such that two optometrists assessed 23 patients each and two assessed 25 patients each.

However, one consultant examined 14 more patients than the other.

Patients ranged in age from 28 to 89 years (median age 68 years). One-third of the patients were classified as glaucoma suspects, $52 \%$ patients had open-angle pathology ranging from mild ocular hypertension to advanced glaucoma and $10 \%$ had narrow-angle pathology. The remaining 5\% had diagnoses that included angle recession, aphakic, uveitic, and steroidinduced glaucoma. The average VF mean deviation was $-1.72 \mathrm{~dB}$ (range $+2.00 \mathrm{~dB}$ to $-15.87 \mathrm{~dB}$ ) with $91 \%$ of patients having a mean deviation of $-6 \mathrm{~dB}$ or better. Of the $70 \%$ of the patients who were being medically treated, $62 \%$ of these were controlled on monotherapy, $31 \%$ on dual therapy, and $7 \%$ on triple therapy.

\section{Clinical management (treatment- and glaucoma-related} outcomes). The optometrists and consultant ophthalmologists were in complete agreement regarding treatment for $97 \%$ of right eyes $(\kappa=0.81, P<0.0001)$ and $96 \%$ of left eyes $(\kappa=0.73, P<0.0001)$ (Table 1$)$.

There was substantial agreement (as defined by kappa) for the glaucoma-related management outcomes (weighted $\kappa=0.65,72 \%$ agreement). Just over half the patients were considered suitable for monitoring in OLGA with either the same or longer follow-up (Table 2), with optometrists being more likely to recommend a reduced length of follow-up. The optometrists and consultants agreed that 14 patients should either be discussed with or referred back to their consultant

Table 1 Agreement regarding treatment decisions prior to the retrospective and consensus review

\begin{tabular}{|c|c|c|c|c|}
\hline \multirow[t]{2}{*}{ Optometrist (right eye) } & \multicolumn{4}{|c|}{ Ophthalmologist (right eye) } \\
\hline & $\begin{array}{l}\text { Continue current treatment } \\
\text { (including no treatment) }\end{array}$ & $\begin{array}{c}\text { Start } \\
\text { treatment }\end{array}$ & $\begin{array}{l}\text { Changeladd } \\
\text { treatment }\end{array}$ & $\begin{array}{l}\text { Reduce } \\
\text { treatment }\end{array}$ \\
\hline Continue current treatment (including no treatment) & 86 & 0 & 0 & 0 \\
\hline Start treatment & 1 & 2 & 0 & 0 \\
\hline Change/add treatment & 2 & 0 & 5 & 0 \\
\hline Reduce treatment & 0 & 0 & 0 & 0 \\
\hline \multirow[t]{2}{*}{ Optometrist (left eye) } & \multicolumn{4}{|c|}{ Ophthalmologist (left eye) } \\
\hline & $\begin{array}{l}\text { Continue current treatment } \\
\text { (including no treatment) }\end{array}$ & $\begin{array}{c}\text { Start } \\
\text { treatment }\end{array}$ & $\begin{array}{l}\text { Changeladd } \\
\text { treatment }\end{array}$ & $\begin{array}{l}\text { Reduce } \\
\text { treatment }\end{array}$ \\
\hline Continue current treatment (including no treatment) & 86 & 0 & 1 & 0 \\
\hline Start treatment & 1 & 2 & 0 & 0 \\
\hline Change/add treatment & 2 & 0 & 4 & 0 \\
\hline Reduce treatment & 0 & 0 & 0 & 0 \\
\hline
\end{tabular}


Table 2 Agreement regarding glaucoma-related management decisions prior to retrospective and consensus review

\begin{tabular}{|c|c|c|c|c|c|}
\hline \multirow[t]{2}{*}{ Optometrist } & \multicolumn{5}{|c|}{ Ophthalmologist } \\
\hline & Discharge? & $\begin{array}{l}\text { OLGA samel } \\
\text { longer follow-up }\end{array}$ & $\begin{array}{l}\text { OLGA reduced } \\
\text { follow-up }\end{array}$ & Discuss & $\begin{array}{c}\text { Refer } \\
\text { (glaucoma) }\end{array}$ \\
\hline Discharge? & 3 & 0 & 0 & 0 & 0 \\
\hline OLGA same/longer follow-up & $1^{\mathrm{a}}$ & 51 & 4 & 3 & 1 \\
\hline OLGA reduced follow-up & 0 & 14 & 1 & 1 & 1 \\
\hline Discuss & 0 & 0 & 1 & 5 & 0 \\
\hline Refer (glaucoma) & 0 & 0 & 1 & 0 & 9 \\
\hline
\end{tabular}

${ }^{a}$ Case notes not available for retrospective review by second consultant.

Table 3 Agreement regarding evaluation of optic-disc stability

\begin{tabular}{|c|c|c|c|c|}
\hline \multirow[t]{2}{*}{ Optometrist (right eye) } & \multicolumn{4}{|c|}{ Ophthalmologist (right eye) } \\
\hline & $\begin{array}{l}\text { Definitely } \\
\text { stable }\end{array}$ & $\begin{array}{l}\text { Probably stable } \\
\text { (limited data) }\end{array}$ & $\begin{array}{l}\text { Probably progressing } \\
\text { (limited data) }\end{array}$ & $\begin{array}{l}\text { Definitely } \\
\text { progressing }\end{array}$ \\
\hline Definitely stable & 53 & 19 & 1 & 1 \\
\hline Probably stable (limited data) & 9 & 7 & 0 & 0 \\
\hline Probably progressing (limited data) & 1 & 1 & 0 & 2 \\
\hline Definitely progressing & 2 & 0 & 0 & 0 \\
\hline \multirow[t]{2}{*}{ Optometrist (left eye) } & \multicolumn{4}{|c|}{ Ophthalmologist (left eye) } \\
\hline & $\begin{array}{l}\text { Definitely } \\
\text { stable }\end{array}$ & $\begin{array}{l}\text { Probably stable } \\
\text { (limited data) }\end{array}$ & $\begin{array}{l}\text { Probably progressing } \\
\text { (limited data) }\end{array}$ & $\begin{array}{l}\text { Definitely } \\
\text { progressing }\end{array}$ \\
\hline Definitely stable & 51 & 15 & 2 & 1 \\
\hline Probably stable (limited data) & 12 & 10 & 0 & 0 \\
\hline Probably progressing (limited data) & 0 & 1 & 2 & 0 \\
\hline Definitely progressing & 0 & 0 & 1 & 0 \\
\hline
\end{tabular}

for a glaucoma-related problem and that 3 were suitable for discharge.

Glaucoma stability (VF, optic discs, and IOP). There was moderate agreement for the evaluation of VF status (right eye 67\%, $\kappa=0.42, P<0.0001$; left eye $70 \%, \kappa=0.50$, $P<0.0001$ ), poor to fair agreement for the evaluation of optic-disc status (right eye $63 \%$, weighted $\kappa=0.17$, $P=0.015$; left eye $66 \%$, weighted $\kappa=0.31, P<0.0001$ ), and moderate to substantial agreement for IOP status (right eye $85.5 \%$, weighted $\kappa=0.60, P<0.0001$; left eye $83 \%$, weighted $\kappa=0.55, P<0.0001)$. Despite weighted kappa values for the evaluation of optic-disc status being low, consultants and optometrists were in partial or complete agreement for $95 \%$ of eyes (Table 3 ). An example of a partial agreement was a classification of 'definitely stable' by one clinician vs 'probably stable' by the other. Of the 20 patients ( 25 eyes) where there was a difference of opinion regarding disc/VF stability, the subsequent management differed in half the cases.

Planned tests (VF, IOP, and day phasing). Overall, very few planned tests were recommended, with percentage agreements ranging 91-98\%. However, optometrists recommended more repeat fields than ophthalmologists (10 vs 5) and there was no agreement about which fields should be repeated.

Retrospective review by second consultant. The optometrists and ophthalmologists disagreed about the clinical management in 27 cases (Table 2), 26 of which were subject to retrospective review as one set of case notes was not available at the time of the study. The second consultant agreed with the optometrist in seven cases and there was a qualified level of agreement in four cases. In all the nine cases where the consultants were in agreement with each other, the optometrist had recommended a shorter length of follow-up and/or repeat VF. However, the consultants commented that the absence of a target pressure in three of these cases may have adversely influenced the optometrist's decision.

Consensus agreement. The remaining six cases were subject to a consensus review by the two consultant ophthalmologists who were of the opinion that the 
optometrists had made acceptable decisions for all the six patients but had been overcautious in two cases, both of which had VF results that were either unreliable or extremely variable, and had been under-cautious in two cases. However, in one of these cases, the consultants qualified their decision with the comment that the optometrist was considered to have taken a pragmatic view that was appropriate for the patient's age.

\section{Part two: analysis of queries/referrals from the OLGA clinic}

In total, 47 referrals or queries to the patient's registered consultant ophthalmologist were generated during the audit period (Table 4). The majority of these were from optometrists 1 and 3 who, between them, managed 75\% of the OLGA clinics at that time. Of the 47 queries, 43 were glaucoma-related and 26 of the patients were actually examined by one of the audit consultants.

Table 4 Summary of queries/referrals generated by the OLGA service during the audit period

\begin{tabular}{lr}
\hline Summary of queries/referrals & Numbers \\
16 January 2008-26 March 2008 & \\
\hline Total number of queries & 47 \\
Optom 1 & 10 \\
Optom 2 & 1 \\
Optom 3 & 27 \\
Optom 4 & 9 \\
Glaucoma-related & 43 \\
Non-glaucoma-related & 4 \\
Number of patients seen by consultant & 26 \\
Notes only reviewed & 20 \\
Number of total agreement & 41 \\
Number of qualified agreement & 6 \\
Number of disagreements & 0 \\
Total number of queries regarding treatment & 31 \\
Change/add/start treatment & 28 \\
Side effects of treatment & 2 \\
Occludable angles & 1 \\
Number of discharge queries & 5 \\
Number of requests for target IOP & 5 \\
Ok to continue monitoring? & 1 \\
Non-glaucoma queries & 3 \\
Neurological field defects & 4 \\
Posterior capsular thickening & 4 \\
Dry eyes requiring punctal plugs & 4 \\
Macular hole & 4 \\
Total number where management was altered as a result of & \\
referral/query & \\
Change/add/start treatment & \\
YAG PI & \\
Shorter review & \\
Fischarged & \\
Punctal plugs fitted & \\
Listed for macular hole surgery & \\
Total number where management was not altered & \\
\hline
\end{tabular}


referrals are accepted from both glaucoma- and nonglaucoma-specialist consultant ophthalmologists who, at the time of the study, numbered 3 and 12, respectively. As the study was conducted prior to the publication of the NICE guidelines, ${ }^{2}$ the optometrists often had to make management decisions consistent with individual ophthalmologist preferences and target pressures, where recommended by the referring ophthalmologist, were often set in the absence of corneal thickness information.

Following the retrospective and consensus review, the optometrists in our study achieved an $81 \%$ level of agreement with the glaucoma-specialist consultant ophthalmologists when making clinical management decisions about the timing of follow-up, the suitability for discharge, and the need to discuss or refer the patient back for a consultant's opinion and/or intervention. This level of agreement increased to $90 \%$ when qualified agreements were included and decisions regarding medical management reached agreement levels of $96-97 \%$. Previous hospital ${ }^{4,11}$ and community ${ }^{8}$ based studies have also reported good to nearly perfect levels of agreement for medical management. In our study, none of the optometrists' decisions was deemed unacceptable, although in two cases, the optometrists were judged to have been under cautious. Both of these patients were in their 80 s and had slightly variable VF. One was being treated for ocular hypertension, having tilted discs and a field defect consistent with an old branch retinal vein occlusion. The other was a normal tension glaucoma suspect. Both patients have subsequently remained stable without requiring a change of treatment and are now on annual review.

On the whole, disagreements tended to occur because our optometrists were more cautious than the ophthalmologists when making decisions about length of follow-up and VF stability. Similar findings were reported in the Bristol shared care glaucoma study. ${ }^{9}$ Although a more guarded approach should not be discouraged in terms of patient safety, there are obviously economic and potential psychological cost implications when patients are seen on a more frequent basis or require additional tests. On the other hand, the ability of our optometrists to recognise those patients who require more specialist intervention, whether it be for glaucomatous or co-existing non-glaucomatous pathology, is essential in minimising the costs of long-term vision loss. The optometrists have also demonstrated their ability to correctly identify those individuals who no longer require follow-up within the HES, which is vital in contributing to the ongoing effort to reduce pressure on the glaucoma clinics and the associated support services.

In terms of the overall assessment of glaucoma status, that is, VF, optic discs, and IOP, the optometrists in our study achieved a moderate to substantial level of agreement in all but one area of their clinical evaluation-optic-disc stability. The fact that the relatively high percentage agreement for optic-disc status was not reflected in the kappa value may have occurred because the majority of discs were classified as stable or probably stable. ${ }^{15}$ None of the previous studies ${ }^{4,9-11}$ included an assessment of optic-disc stability and the results for VF analysis varied considerably, with Banes et $a^{4}$ reporting a fair level of agreement $(55 \%, \kappa=0.33)$ and Ho and Vernon ${ }^{11}$ reporting an almost perfect level of agreement $(90.2 \%, \kappa=0.84)$ — a result that may have been influenced by the fact that the ophthalmologist was not masked to the optometrist's decisions. Notwithstanding, the difficulty in correctly identifying progressive optic disc and VF changes has previously been well documented and the agreement levels achieved by our optometrists are similar to those of other studies comparing glaucoma specialists. ${ }^{4,16-18}$ Differences in opinion regarding the stability of optic discs and VF will occur because of the subjective nature of such assessments but do not always lead to differences in management decisions. The fact that the consultant ophthalmologists initially disagreed with each other in more than half the cases that were retrospectively reviewed only serves to highlight the difficult and variable nature of glaucoma management, even in a population considered to be at low risk.

\section{Study limitations}

Any study performed within the confines of a normal clinical setting will be subject to limitations. Although we acknowledge that our patient numbers are small compared with the majority of the previous studies, ${ }^{4,9-11}$ all but one of these studies ${ }^{4,10,11}$ required the ophthalmologists to make decisions based on a retrospective review of clinical data that had been collected by other health professionals. By adopting a similar methodology, it would have been possible to include a larger number of patients and provide a quantifiable measure of agreement between the two ophthalmologists-an advantage of the Banes study. ${ }^{4}$ However, the ability of the ophthalmologists to examine the patients and, in particular, the optic discs in vivo was considered by us, and by Azuara-Blanco et $a l^{8}$ who conducted a study of similar size, to be an essential part of the study design. Despite optic-disc photography being an integral component of the OLGA examination, such images lack three-dimensional information and can vary in quality, particularly in an older population with media opacities and smaller pupils. Agreements regarding other aspects of the clinical assessment, for example, gonioscopy, were not formally assessed as they were considered to have been independently verified as part of the glaucoma diploma. The decision not to 
include junior ophthalmologists to act as an additional reference standard was made on the basis that they were unlikely to have completed their glaucoma training and that their work within a consultant-led clinic enables them to have immediate access to an expert opinion. Unlike the study by Ho and Vernon, ${ }^{11}$ the optometrists in our study were aware that they were being assessed and unavoidable restrictions on clinician availability led to unequal distribution of patients between the ophthalmologists, potentially introducing an element of bias. As these constraints also made it impractical to obtain a direct measure of agreement between the two ophthalmologists, the second consultant retrospective review was incorporated into the study design.

Differences in opinion will always occur within the clinical setting, irrespective of the speciality and the level of expertise. However, our results suggest that specially trained optometrists with the appropriate qualifications and experience are capable of making glaucoma assessment and management decisions that would strongly support an increasing role for them in a service that is overburdened and under great pressure to expand to meet the demands created by both existing and future glaucoma and glaucoma-suspect patients.

\section{Summary}

What was known before

- Specially trained community optometrists are capable of making satisfactory decisions regarding the diagnosis, treatment, and monitoring of glaucoma patients but some cases of glaucoma may be missed and a significant element of supervision may be required.

- Specially trained optometrists working within a consultant-led glaucoma outpatient department are able to make clinical management decisions that are at least as good as those of other medical clinicians when compared with glaucoma-specialist consultant ophthalmologists retrospectively reviewing clinical data.

- Reported agreement between optometrists and ophthalmologists regarding glaucoma stability has been variable.

What this study adds

- Specially trained and accredited optometrists working independently within the hospital environment monitoring glaucoma and glaucoma-suspect patients are capable of making clinical management decisions that are in close agreement with those of glaucoma-specialist consultant ophthalmologists based on a clinical examination of the patient.

- Agreement between such optometrists and ophthalmologists regarding glaucoma stability is similar to that of other studies, which have compared glaucoma specialists.

- Optometrists may act more cautiously when working independently but are able to correctly identify those individuals requiring a more specialist opinion and/or intervention and those who no longer require follow-up within the Hospital Eye Service.

\section{Conflict of interest}

The authors declare no conflict of interest.

\section{Acknowledgements}

We would like to thank the College of Optometrists, and in particular, Beverley Hancock, who provided the extremely valued services of the statistician, Dr Sayeed Haque, under the $i P R O$ scheme. We would also like to thank Professor D Henson for his comments on the manuscript.

\section{References}

1 National Patient Safety Agency. Rapid response report: preventing delay to follow up for patients with glaucoma. NPSA/2009/RRR004. 11-6-2009.

2 National Institute for Health and Clinical Excellence. Glaucoma: diagnosis and management of chronic open-angle glaucoma and ocular hypertension 2009.

3 Marks J. An optometric led glaucoma assessment service. Optom Pract 2007; 8: 57-62.

4 Banes MJ, Culham LE, Bunce C, Xing W, Viswanathan A, Garway-Heath DF. Agreement between optometrists and ophthalmologists on clinical management decisions for patients with glaucoma. $\mathrm{Br} J$ Ophthalmol 2006; 90: 579-585.

5 Henson DB, Spencer AF, Harper R, Cadman EJ. Community refinement of glaucoma referrals. Eye 2002; 16: 1-6.

6 Bourne RRA, French KA, Chang L, Borman AD, Hingorani M, Newsom WD. Can a community optometrist-based referral refinement scheme reduce false-positive glaucoma hospital referrals without compromising quality of care? The community and hospital allied glaucoma network evaluation scheme (CHANGES). Eye 2010; 24: 881-887.

7 Devarajan N, Williams GS, Hopes M, O'Sullivan D, Jones D. The Carmarthenshire glaucoma referral refinement scheme, a safe and efficient screening service. Eye 2011; 25: 43-49.

8 Azuara-Blanco A, Burr J, Thomas R, Maclennan G, McPherson S. The accuracy of accredited glaucoma optometrists in the diagnosis and treatment recommendation for glaucoma. Br J Ophthalmol 2007; 91: 1639-1643.

9 Gray SF, Spry PGD, Brookes ST, Peters TJ, Spencer IC, Baker IA et al. The Bristol shared care glaucoma study: outcome at follow up at 2 years. Br J Ophthalmol 2000; 84: 456-463.

10 Syam P, Rughani K, Vardy SJ, Rimmer T, Fitt A, Husain $\mathrm{T}$ et al. The Peterborough scheme for community specialist optometrists in glaucoma: a feasibility study Eye 2010; 24: 1156-1164.

11 Ho S, Vernon SA. Decision making in chronic glaucoma optometrists vs ophthalmologists in a shared care service. Ophthalmic Physiol Opt 2011; 31(2): 168-173.

12 Kelly S, Rimmer T, Bailey C, Gibson J, Sparrow JM. New to Follow up (N:F) Ratios in Ophthalmology Outpatient Services. The Royal College of Ophthalmologists: London, 2011.

13 Tuck MW, Crick RP. The projected increase in glaucoma due to an ageing population. Ophthalmic Physiol Opt 2003; 23: 175-179. 
14 Vernon SA, Adair A. Shared care in glaucoma: a study of secondary care lead schemes in England. Eye 2010; 24: 265-269.

15 Feinstein AR, Cicchetti DV. High agreement but low kappa: I. The problems of two paradoxes. J Clin Epidemiol 1990; 43(6): 543-549.

16 Viswanathan AC, Crabb DP, McNaught AI, Westcott MC, Kamal D, Garway-Heath DF et al. Interobserver agreement on visual field progression in glaucoma: a comparison of methods. Br J Ophthalmol 2003; 87: 726-730.
17 Chauhan BC, Hutchinson DM, Artes PH, Caprioli J, Jonas $\mathrm{JB}$, LeBlanc RP et al. Optic disc progression in glaucoma: comparison of confocal scanning laser tomography to optic disc photographs in a prospective study. Invest Ophthalmol Vis Sci 2009; 50: 1682-1691.

18 Jampel HD, Friedman D, Quigley H, Vitale S, Miller R, Knezevich $\mathrm{F}$ et al. Agreement among glaucoma specialists in assessing progressive disc changes from photographs in open-angle glaucoma patients. Am J Ophthalmol 2009; 147(1): 39-44. 